\title{
Spatial Pattern of Traffic Induced Carbon Monoxide and Potential Health Risk in Karachi
}

\author{
Imran Ahmed Khan ${ }^{\mathrm{a}^{*}}$ and Mudassar Hassan Arsalan ${ }^{\mathrm{b}}$ \\ ${ }^{a}$ Department of Geography, University of Karachi, Karachi 75270 - Pakistan \\ ${ }^{\mathrm{b}}$ Geoinformatics and Sustainable Development Research Lab, Institute of Space \\ and Planetary Astrophysics, University of Karachi, Karachi 75270. \\ * Corresponding author Imran Ahmed Khan \\ E-mail address: imranak32@uok.edu.pk; imranak32@hotmail.com
}

\begin{abstract}
:
This paper aims to investigate carbon monoxide (CO) concentrations on roadways of Karachi, potential blood levels carboxy-hemoglobin $(\mathrm{COHb})$ in Karachi. Geographical information system (GIS) was used for spatial analysis of diseases potentiality while an interpolation technique has been applied for surface generation with town boundaries and later evaluates risk areas. The higher concentration of carbon monoxide in the ambient is mainly due to automobile emissions. The City center and CBD areas are more perilous.
\end{abstract}

Keywords: carbon monoxide; $\mathrm{COHb}$; air pollution; GIS interpolation; spatial analysis; respiratory diseases

\section{Introduction:}

Atmosphere is very energetic and this dynamism is changing at an alarming rate since the beginning of industrial revolution. Nowadays atmospheric pollution is a major environmental health problem. Continuous growth of human induced unchecked sources of pollution is the critical point of this growing problem. Besides increasing pollution there is an increasing demand for the early and reliable detection of adverse effects caused by this pollution so that effective monitoring and control measures could be introduced.

One of the most fundamental and major influence affecting on us is fresh and clean air, its impact on quality and length of one's life. Due to urban life style respiratory diseases are on the rise, urban life style act on human health. Urbanization in the modern sense of the term is the 
picture of blocks of flats, traffic jams, air pollution, noise nuisance, and growth of slums and avalanches of refuse (Scholz, 1983, Helgesonet al, 2017). As a result, some dangerous chemicals were deliberately introduced in the environment. These substances in such quantities and of such duration are liable to cause harm to human, plant or animal life, or damage human made materials and structures, or bring changes in the climate, or interfere with the comforts of life or property or effect other human activities. Recent evidence indicates that motorized vehicles are major source of air pollution in urban areas. It is estimated that road traffic contributes $60 \%$ of air pollution in urban areas. Traffic in metropolitan area is the leading cause of pollutants emission especially for $\mathrm{CO}$ and also for NOx, VOCs, SOx and particulate (WHO, 2006; WHO, 2007; WAS, 2006; Imtiaz et al, 2015).

Carbon monoxide is a byproduct of fossil fuel combustion. In central part of cities where traffic jams occur, high concentration of this pollutant will show up and problems of this gas are more serious. Discharged CO from motorized vehicles and other sources to air will have in direct effects on climate change and in addition adverse health effects on exposed humans(AGU, 1995, Nair et al, 2017). Carbon monoxide is not highly soluble in water, so it penetrates in lungs and transfers into the blood stream, combines with hemoglobin to form Carboxy-hemoglobin (COHB), which impairs the oxygen carrying capacity of the blood. Carbon monoxide enters in the blood stream and reduces the delivery of oxygen to the body's organs and tissues. The threat to human health is most serious for those who suffer from cardiovascular diseases. Exposure to elevated carbon monoxide level is associated with impairment of visual perception, difficulties in respiration, work capacity, manual dexterity, learning ability and performance of complex tasks.

The effects of $\mathrm{CO}$ depend on concentration, exposure time, and health status of people, their age and activity (Kumar, 2017). Long-term exposure to low concentration of CO can have similar effects to short-term exposure with high concentration. CO loading in blood reduces volume if blood distributed to body tissues. As a result, ability of healthy individuals is reduced for running, working, walking and other activities. The symptoms of exposure to CO start with headache, tiredness, dizziness, nausea, vomiting and drowsiness and in very acute situation; unconsciousness and death will follow. In WHO and American National Standards of ambient air, 8-hr mean concentration of CO gas should not be exceeded from $9 \mathrm{ppm}\left(10, \mathrm{mg} / \mathrm{m}^{3}\right)$ (WHO, 1998; WHO, 1999). Wayne and Ming-Ho convey the adverse effects of CO on human health 
and make estimated values of $\mathrm{COHb}$ in the blood after exposing a certain time. Thus $2-5 \%$ blood $\mathrm{COHb}$ may affect the central nervous system, impair time interval discrimination, cause visual acuity, affect discrimination of brightness and may change certain other psychomotor functions. When this situation is supplemented with other gaseous pollutants of automobile exhaust like hydrocarbons, oxides of Sulphur, nitrogen oxides, dust, etc., a miserable picture can be visualized.

These environmental deprivation processes continue in Karachi in which air pollution is the major concern that is dangerously affecting the urban areas of the metropolis. Karachi is one of the leading polluted cities in the world. As a massive urban and industrial area there are three human induced dominating air pollution sources, vehicular traffic, Industrial manufacturing units and open air garbage burning. These sources release thousands of tons of toxic gases and particulate matters into atmosphere of Karachi (Qureshi, 1997).

\section{Geographical Information System (GIS) and health studies:}

In several health studies GIS and associated spatial statistics have applied by researchers (Gatrell and Loytonen, 1998; Moore and Carpenter, 1999 and Jerrett et al., 2003). GIS is a system that could be characterize as a spatial analysis method and system for the organization, storage, transformation, retrieval, analysis, and display of data (DeMers, 1997; Aronoff, 1989).where space or spatial location is considered important e.g., the incidence of a specific health state or disease in relation to a pollution source (Arsalan,2003). GIS now recognized itself as a basic tool within the area of public health and environmental studies that is use in demonstration and analysis of disease incidence data in map form in many studies (Lawson, 2001; Jerrett et al., 2003).

The skill to design the hazard of disease cartographically provides community health officials' improved information on where to target programs of disease anticipation. This similar skill to plot risk can be built upon by relating hazards to variables such as social characteristics, pollution and respiratory health, that can then be used as environmental difference indication (Jerrett et al., 1997). The mapping of disease forecasting in public health supports in pre-decisive potential problem areas that report to surveillance and participation plans. The majority of recent 
action focuses on creating maps that demonstrate bigger environmental risks (Khan et al, 1993 and 1996; Shareefet al, 2011; Khan et al, 2011; Holton, 2004).

\section{Material and method}

\section{a) Base Mapping}

The base map is the control document from which various other maps are developed. Initially base map of the study area by using ARCGIS 9.0 has done, in order to put the necessary information acquired during the study. Karachi development authority (KDA) is responsible authority in development of Karachi. in the study we used Karachi map of KDA as the basic source to develop the base map especially in terms of boundaries of UCs, and land use blocks and road development, city government Karachi is local authority for administration 18 towns are under his authority and 6 cantonment areas and some other authorities are also having some areas of Karachi.

Satellite imageries are the helpful source to describe the real position of a particular area mainly in terms of Land cover and Land use. In this study, we use a Landsat satellite image of Karachi, to develop the maps for study area in GIS set-up. In this study published town boundaries maps were used and geo-referenced, as a result the base map was developed.

\section{b) CO monitoring}

The sampling plan was done according to the 36 locations, which are shown at the Karachi map in heavy traffic areas (Figure1). Concentration of carbon monoxide is measured by Snift CO Analyzer (Model 50). The Analyzer is ideal for measuring the level of carbon monoxide in ambient air and it samples the surrounding air and shows the detected concentrations of carbon monoxide in ppm. During all the measurements, the meter was kept at about $1.2 \mathrm{~m}$ above the ground level. At each site, level of CO in the ambient air was taken at an interval of 10 minutes and a set of ten readings were noted in a period of about 2 minutes and repeated after every 8 minutes. The data was generated at 36 locations from 08 AM to $06 \mathrm{PM}$, at each site. Thus $60 \mathrm{CO}$ point's readings were taken at each of 36 locations, making a total of 2160.At each location, level of carbon monoxide was measured continuously from 8:00 to 18:00. $8 \mathrm{hr}$ TWA averages values were calculated from those readings. 
To find out the variation amount of $\mathrm{CO}$ in each station at different times of the day, hourly concentration of $\mathrm{CO}$ averaged for the timing of 8-18 hours was measured for comparing with WHO guidelines. Measured Time Weighted Average (TWA) values for 8 hour and evaluated equilibrium concentration of blood $\mathrm{COHb}$, along with the recorded TWA 8 hour values at these sites are in Table 1.

\section{c) GIS Interpolation and Risk evaluation}

Geographic Information Systems having several tools to analysis the scenario. One of the tools using in GIS there is an Interpolation Technique through which if we know some values of a variable we could generate the values where we do not know, so a continuous surface may produce.The Inverse Distance Weighted (IDW) methods is referred to as deterministic interpolation methods because it allocates values to locations based on the surrounding measured values and on specified mathematical formulas that determine the smoothness of the consequential surface. Interpolation has further classified into IDW, Spline and Kriging, here we used IDW method. CO values calculate through interpolation techniques by using ArcGIS 9.0, 36 point of measuring $\mathrm{CO}$ used for inverse distance weightage (IDW), after surface generation (Figure 2), first calculate values town wise then using mean vales of CO through interpolation then evaluate $\mathrm{COHb}$ values by using equation following describe, later these $\mathrm{COHb}$ values linked with town wise table values that finally used for map representation and potential risk areas (Figure 3). The equilibrium percentage of $\mathrm{COHb}$ in bloodstream of a person continually exposed to an ambient air CO concentration of less than $100 \mathrm{ppm} \mathrm{CO}$ was estimated by using following equation(Wayne and Ming-Ho, 2004).

\section{COhb Blood Level $\%=0.16 \times$ Concentration +0.5}

\section{Results and Discussion:}

Table 1, shows that depending upon the location and time, TWA values, evaluated for $8 \mathrm{hr} 3$ to 71 ppm.Concentration of $\mathrm{CO}$ at 18 locations was found very high and much above the permissible limit of $9 \operatorname{ppm}\left(10 \mathrm{mg} / \mathrm{m}^{3}\right)$ by the World Health Organization (WHO, 1998; WHO,1999; Wayne et al, 2007). Constant exposure of such a high level CO may result in variety adverse effects of roadside traders and workers. 
The reasons of high $\mathrm{CO}$ and other gaseous pollutants in ambient air are lack of regulatory laws to gaseous pollutants in the ambient air on the roads. Earlier indigenous studies of $\mathrm{CO}$ and its relation with traffic define some classic examples (Arsalan, 2003). Even today the traffic volume and $\mathrm{CO}$ values are strong relation in the study area (Figure4). The other reasons of high concentration of air pollutants on the streets are poor model of vehicles, poor maintenance, narrow roads and uneven road surfaces, rash driving, poor education of vehicle drivers, especially commercial vehicle drivers, poor geometrics, frequent traffic jams and congestion aggravated the situation.During traffic jams or signal light, the carbon monoxide concentration shoots up abruptly with in frictions of a minute and becoming a health hazards for human beings. The concentration of carbon monoxide at a place varies with traffic density and type and condition of vehicles in the given traffic stream. Other factors such as wind velocity, wind direction, humidity and temperature are also important. Higher the wind velocity and more open area around the location lower the concentration of carbon monoxide. Similarly, high temperature along with the higher wind velocity would increase the rate of diffusion, which would enhance the dissipation of carbon monoxide soon after the emission.

Important locations such as Safoora Goth, Sohrab Goth, Water Pump, MosamiatChowrangi, Muzzafarabad Landhi, Korangi crossing, Korangi singer Chowrangi, KamranChowrangi, Numaish Chowrangi, NIPA Chowrangi, and Aisha Manzil Chowrangi are quite open places as compared to the rest of locations; this is why the concentration of $\mathrm{CO}$ at these sites is lower than that observed at other sites. It is a general trend that emissions of carbon monoxide in the streets vary with the traffic density. Concentration of $\mathrm{CO}$ in the streets generally increases with the increase in traffic density in the morning when people go to their offices and students their institutions, thereafter when the traders/ businessman go to their shops/workplaces. Commercial activities reach at their peak level between 11:00-15:00h and at 16:00h the traffic density gets lower thus reducing the $\mathrm{CO}$ emission, after 17:00h the traffic density again increases and subsequently raising the $\mathrm{CO}$ level. Thus it has been observed that an abrupt and comparatively higher increase in CO occurs after 17:00h with a little rise in traffic density (Khan et al, 1993).

Table 2 shows the town wise CO mean values varies from $5.4 \mathrm{ppm}$ to $39.3 \mathrm{ppm}$ and only five towns having within permissible limit whereas all remaining towns are higher than permissible 
limit that is $9 \mathrm{ppm}$. Overall in the study area the CO mean value is near about $20 \mathrm{ppm}$ that is double of the permissible limit. Regarding estimated $\mathrm{COHb}$ values that ranges from $1.36 \%$ to $6.79 \%$ and overall value found is 3.64\%. Five towns namely DHA, Saddar, Jamshed, Lyari and Liaquatabad towns are highly vulnerable areas where people are at great danger concerning respiratory and heart related diseases.

\section{Conclusion:}

GIS based this study explain that the concentration of carbon monoxide in the ambient air on the busy roads of CBD zone of Karachi is very high. High road density enables overall town average with high $\mathrm{CO}$ values.Resulting in average $\mathrm{COHb}$ level might also rise that may possibly cause high rate of respiratory and heart related diseases.

\section{References:}

1. AGU: (American Geophysical Union), (1995). Decline in atmospheric CO raises questions about its cause. J. Earth in space 8(3): 7-12.

2. Aronoff S., (1989).Geographical Information Systems: A Management Perspective, WDL Publications, Ottawa

3. Arsalan M.H., (2002),"Monitoring Spatial Pattern of Air Pollution in Karachi Metropolis: A GIS and Remote Sensing Perspective “.Ph. D. Thesis, University of Karachi, Pakistan.

4. DeMers M.N., (1997) Fundamentals of Geographic Information Systems, Wiley, New York.

5. Gatrell, A.C., Loytonen, M., (1998). GIS and Health Research: An Introduction. GIS and Health. Taylor \& Francis, London, pp. 3-16.

6. Ghauri B., Lodhi A., and Salam M., 1999, Assessment of Air Quality in the Metropolitan Karachi, Pakistan Space and Upper Atmosphere Research Commission with Collaboration of Karachi Electric Supply Coorporation -Thermal Power Plant, Bin Qasim, Karachi

7. Helgeson, S. A., Wilson, M. E., \& Guru, P. K. (2017). Normal carboxyhaemoglobin level in carbon monoxide poisoning treated with hyperbaric oxygen therapy. BMJ Case Reports, 2017, bcr-2017. 
8. Holton W.C., (2004). Rich map poor map, Environmental Health Perspectives 112 pp. A177-A179.

9. Imtiaz, F., Alam, M., Kumar, V., Arif, S., \& Masood, M. (2015). Pulmonary Function Test in Car Wash Workers of Karachi, Pakistan. Epidemiology: Open Access, 2015.

10. Jerrett M., Eyles J., Cole D. and Reader S., (1997), Environmental equity in Canada: an empirical investigation into the income distribution of pollution in Ontario, Environment and Planning A29 pp. 1777-1800.

11. Jerrett,M. R. Burnett, M. Golberg, D. Krewski, R. Catalan, P. Kanarolou, C. Giovis and N. Finkelstein, (2003). Spatial analysis for environmental health research concepts, methods, and examples, Journal of Toxicology and Environmental Health Part A 66,pp. $1783-1810$

12. Khan A.R., Akif M. and Khattak M.A., (1993). PCSIR Peshawar report.

13. Khan, A. R., Akif, M., \& Khattak, M. A. (1996). Atmospheric pollution due to carbon monoxide from vehicular exhaust in Peshawar. Jour. Chem. Soc. Pak. Vol, 18(3).

14. Khan, I. A., Arsalan, M. H., Siddiqui, M. F., Hashmi, D. R., Zeeshan, S., \& Siddiqui, B. A. (2011). Association of Asthma with Carbon Monoxide Concentrations on the Roads of Karachi and Potential Blood Level of Carboxy Haemoglobin. Fuuast Journal of Biology, 1(1).

15. Kumar, A. (2017). Wavelet Analysis of Air Pollution due to Carbon Monoxide. International Journal of Advance Research, Ideas and Innovations in Technology, 3(4), 131-136.

16. Lawson A.B., (2001). Disease map reconstruction, Statistics and Medicine 20, pp. $2183-2204$

17. Moore D.A. and Carpenter T.E., (1999). Spatial analytical methods and geographic information systems: use in health research and epidemiology, Epidemiology Review 21, pp. 143-161.

18. Nair, A. J., Nandini, M., Adappa, S., \& Mahabala, C. (2017). Carbon monoxide exposure among police officers working in a traffic dense region of Southern India. Toxicology and industrial health, 33(1), 46-52.

19. Qureshi N.,(1997), Atmospheric Pollution in Karachi 40 Percent Higher than other Cities, Frontier Post, June 07, Karachi.

20. Scholz F., (1983), Urbanization in the Third World: The Case of Pakistan, Applied Geography and Development, 21, pp. $7-34$. 
21. Shareef, A., Hashmi, D. R., Azam, M., \& Khan, I. A. (2011). Investigation of Carbon Monoxide at Heavy Traffic Intersections of Karachi (Pakistan) using GIS to Evaluate Potential Risk Areas for Respiratory and Heart Diseases.

22. WAS, (World Academy of Science) (2006).Engineering and technology, volume 17 December, ISSN 1307-6884.

23. Wayne G. Landis and Ming-Ho Yu, (2004). Introduction to environmental toxicology: impacts of chemical upon Ecological System.

24. Wayne R.Ott, Anne C. Stinemann and Lance A Wallace, (2007). Exposure Analysis, Published by Taylor and Francis group, 117,

25. WHO, (1998). CEHA, Air quality standards, Netherlands, 24:6-7,.

26. WHO, (1999) Environmental health Criteria-No. 213-Carbon monoxide, WHO, Geneva,.

27. WHO, (2006). Air Quality Guidelines. Global update 2005.World Health Organization 2006.http://www.euro.who.int/Document/E90038.pdf.

28. WHO, (2007). Global estimates of burden of disease caused by the environmental and occupational

risks

http://www.who.int/quantifying ehimpacts/global/urbair/en/index.html. 
Table 1: Carbon Monoxide Level

\begin{tabular}{|c|c|c|}
\hline S No & LOCATION & TWA $8 \mathrm{hr}$ \\
\hline 1 & Liaquat Abad & 71 \\
\hline 2 & Teen Hatti & 69 \\
\hline 3 & Dak Khanna & 63 \\
\hline 4 & Tibet Center & 61 \\
\hline 5 & Bolton Market & 41 \\
\hline 6 & Empress Market & 39 \\
\hline 7 & Numaish & 37 \\
\hline 8 & Eid Gah & 32 \\
\hline 9 & Nipa & 20 \\
\hline 10 & Nagan Chowrangi & 18 \\
\hline 11 & Sohrab Goth & 18 \\
\hline 12 & Tower & 18 \\
\hline 13 & Bilal Colony & 16 \\
\hline 14 & Aisha Manzil & 15 \\
\hline 15 & Safora Goth & 15 \\
\hline 16 & Mosamiat Chock & 14 \\
\hline 17 & Safari Park & 13 \\
\hline 18 & Water Pump & 13 \\
\hline 19 & Nazimabad No 2 & 11 \\
\hline 20 & Nauras Chowrangi & 9 \\
\hline 21 & Urdu Sc College & 9 \\
\hline 22 & Hassan Square & 8 \\
\hline 23 & Korangi Crossing & 7 \\
\hline 24 & Muslimabad & 7 \\
\hline 25 & Kamran Chowrangi & 6 \\
\hline 26 & Murtaza Chowrangi & 6 \\
\hline 27 & Korangi (51 C) & 5 \\
\hline 28 & Korangi $21 / 2$ & 5 \\
\hline 29 & Landhi 89 & 5 \\
\hline 30 & Muzzafarabad & 5 \\
\hline 31 & Defence & 4 \\
\hline 32 & Karimabad & 4 \\
\hline 33 & Brookes Chowrangi & 3 \\
\hline 34 & Clifton & 3 \\
\hline 35 & PCSIR Main Gate & 3 \\
\hline 36 & Singer Chowrangi & 3 \\
\hline
\end{tabular}


Table 2: Appraised Risk Areas

\begin{tabular}{|l|c|c|}
\hline High Risk Town & CO Mean (IDW) & $\begin{array}{l}\text { Evaluated COHB Blood Level } \\
\text { \%(Estimation) }\end{array}$ \\
\hline DHA (partly) & 28.83 & 5.11 \\
Jamshed Town & 33.26 & 5.82 \\
Liaquatabad & 39.3 & 6.79 \\
Lyari & 37.04 & 6.43 \\
Saddar & 30.3 & 5.35
\end{tabular}




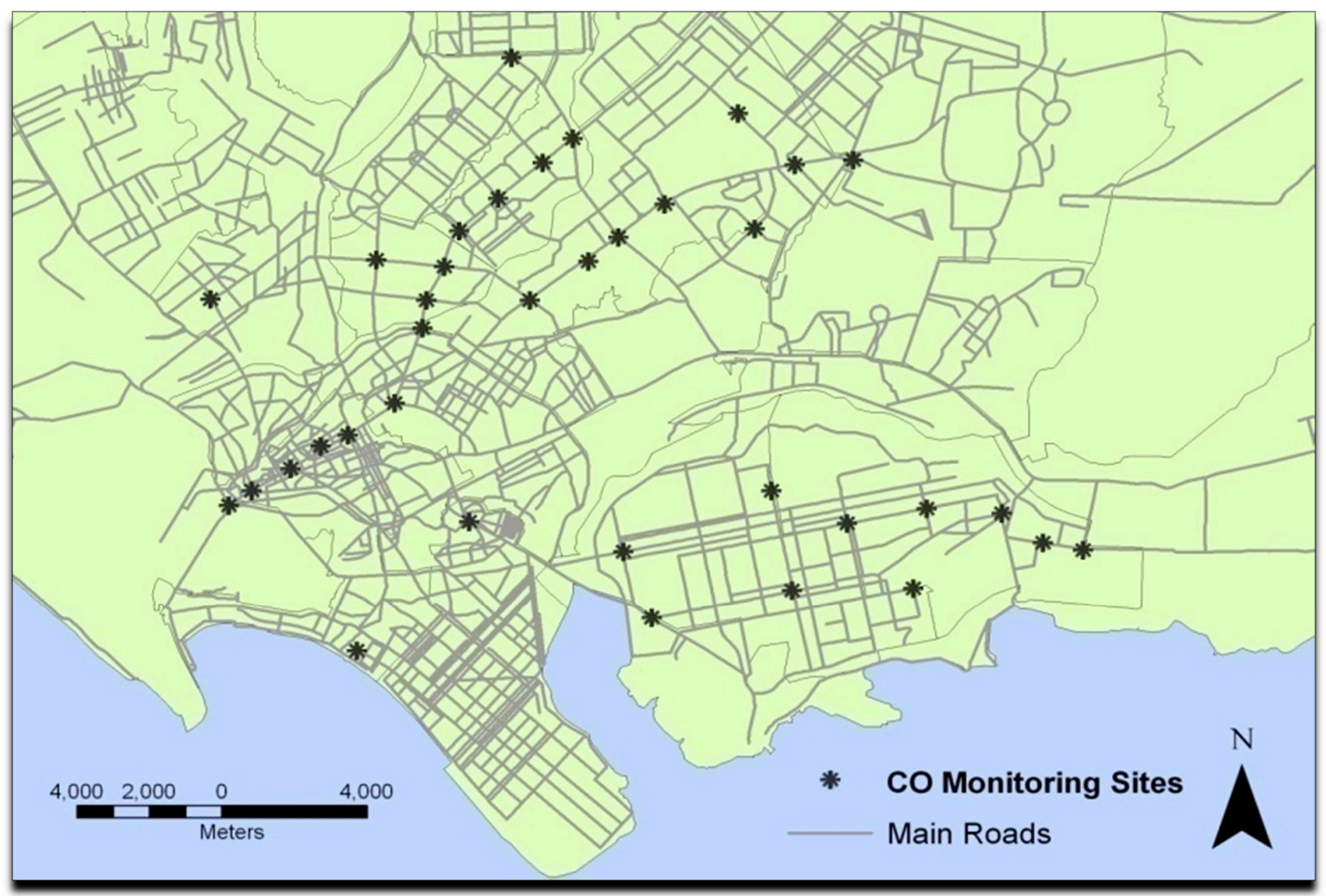

Figure 1: Karachi Major Roads and CO Sites 


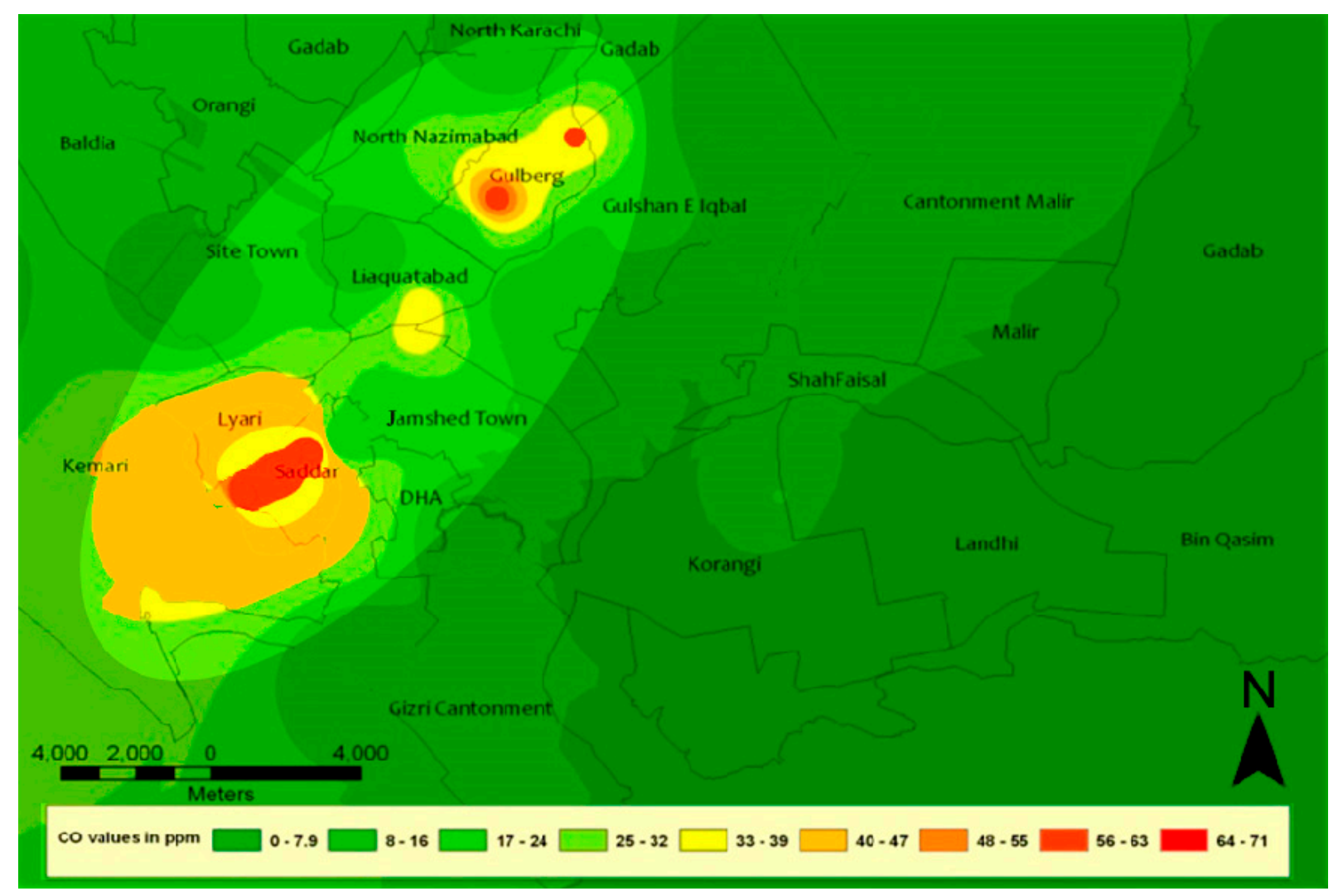

Figure2: Interpolated Surface of CO 


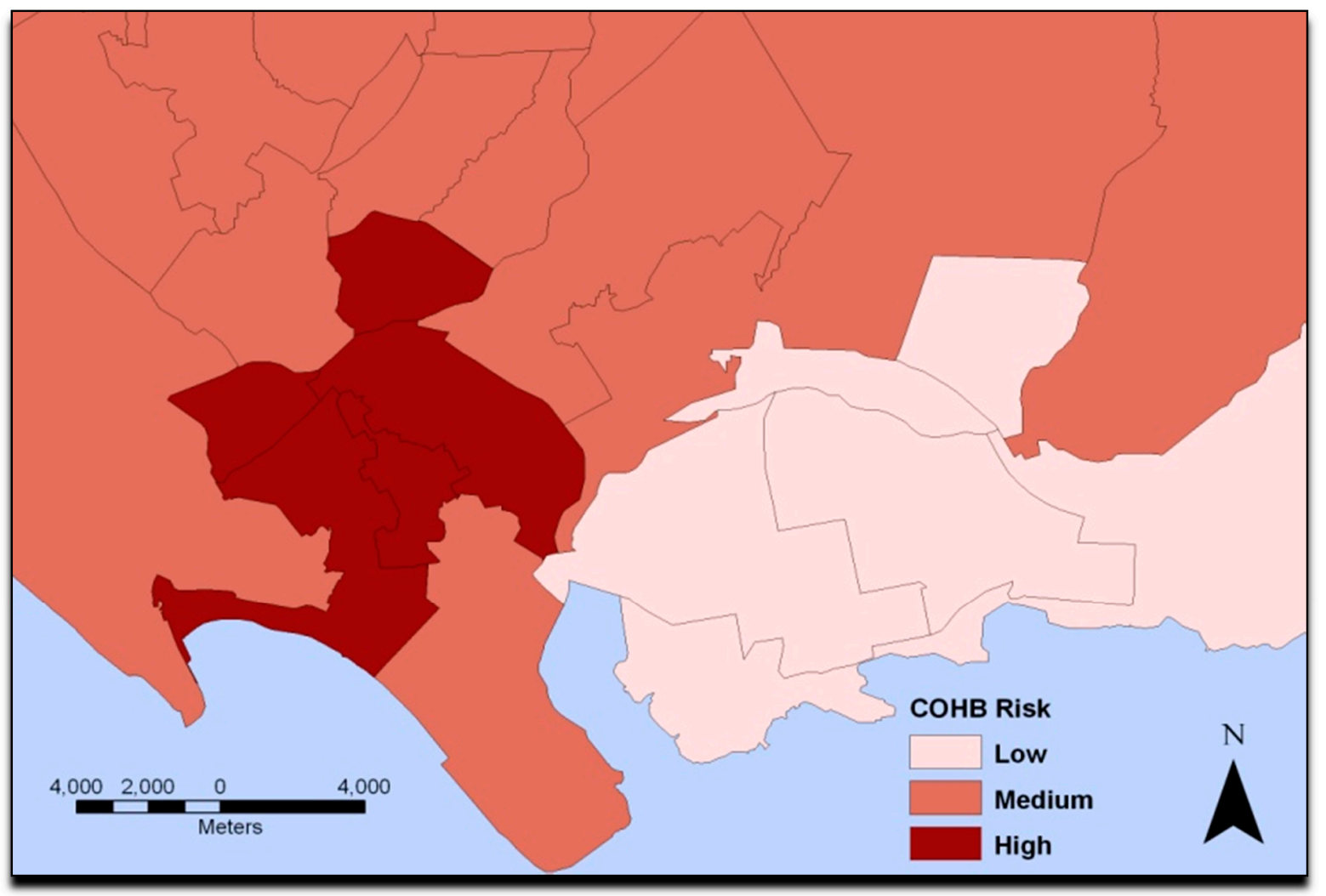

Figure3: Town wise $\mathrm{COHb}$ Distribution and potential risk areas 


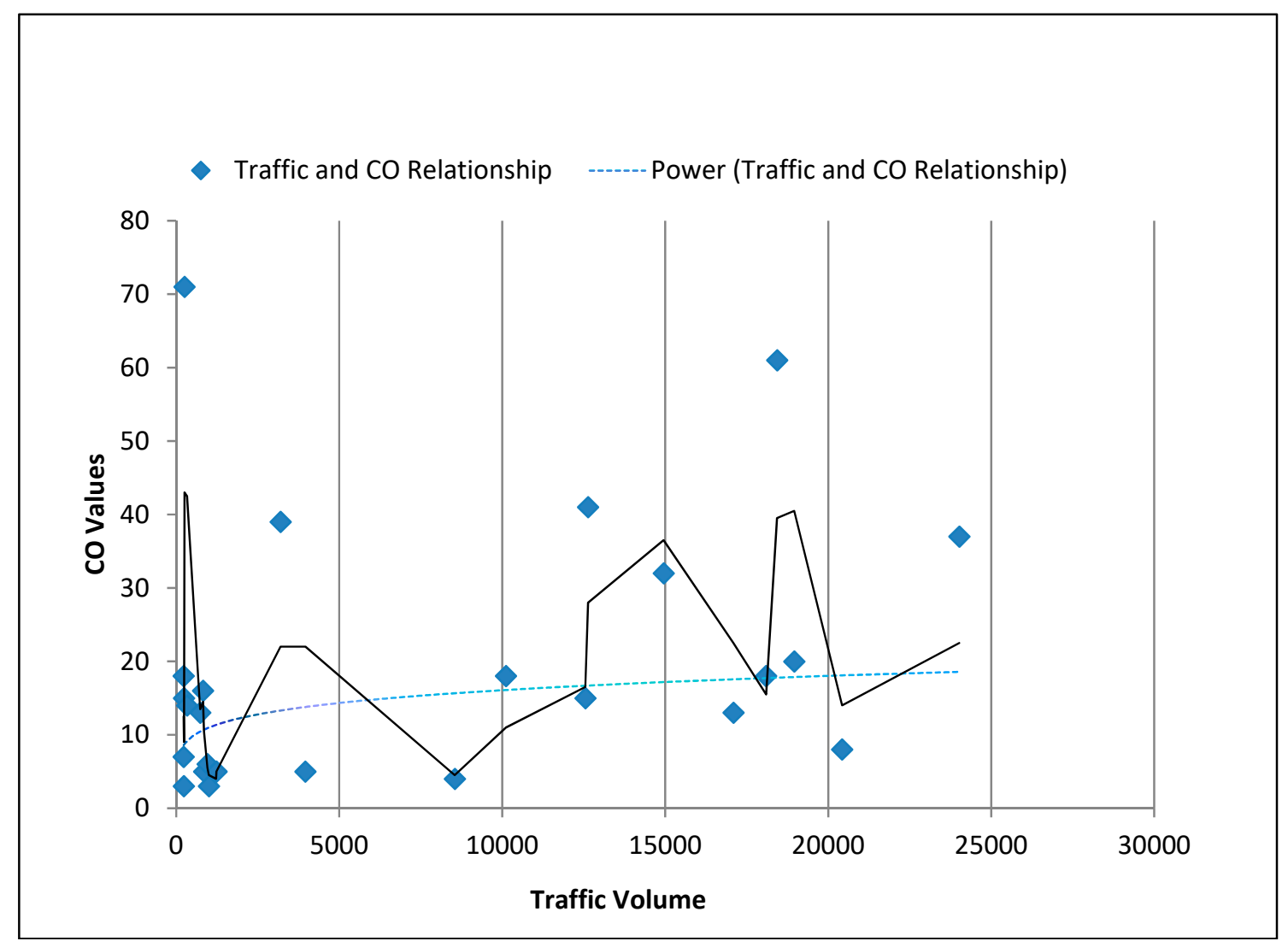

Figure 4: Traffic Volume and CO Relationship in Karachi 